\title{
Oral versus intramuscular administration of vitamin B12 for the treatment of patients with vitamin B12 deficiency: a pragmatic, randomised, multicentre, non-inferiority clinical trial undertaken in the primary healthcare setting (Project OB12)
}

Teresa Sanz-Cuesta ${ }^{*}$, Paloma González-Escobar², Rosario Riesgo-Fuertes ${ }^{3}$, Sofía Garrido-Elustondo ${ }^{4}$, Isabel del Cura-González ${ }^{5}$, Jesús Martín-Fernández ${ }^{6}$, Esperanza Escortell-Mayor ${ }^{7}$, Francisco Rodríguez-Salvanés ${ }^{8}$, Marta García-Solano ${ }^{9}$, Rocío González-González ${ }^{10}$, María Ángeles Martín-de la Sierra-San Agustín ${ }^{11}$, Carmen Olmedo-Lucerón ${ }^{12}$, María Luisa Sevillano Palmero ${ }^{13}$, Carmen Mateo-Ruiz ${ }^{14}$, Beatriz Medina-Bustillo ${ }^{15}$, Antonio Valdivia-Pérez ${ }^{16}$, Francisca García-deBlas-González ${ }^{17}$, José Enrique Mariño-Suárez ${ }^{18}$, Ricardo Rodríguez-Barrientos ${ }^{19}$, Gloria Ariza-Cardiel ${ }^{20}$, Luisa MaríaCabello-Ballesteros ${ }^{21}$, Elena Polentinos-Castro ${ }^{22}$, Milagros Rico-Blázquez ${ }^{23}$, Ma Teresa Rodríguez-Monje ${ }^{24}$, Sonia Soto-Díaz ${ }^{25}$, Susana Martín-Iglesias ${ }^{26}$, Ramón Rodríguez-González ${ }^{27}$, Irene Bretón-Lesmes ${ }^{28}$, María Vicente-Herrero ${ }^{29}$, Jesús Sánchez-Díaz ${ }^{30}$, Tomás Gómez-Gascón ${ }^{31}$, Mercedes Drake-Canela ${ }^{32}$, Ángel Asúnsolo-del Barco ${ }^{33}$ and OB12 Group ${ }^{34}$

\begin{abstract}
Background: The oral administration of vitamin B12 offers a potentially simpler and cheaper alternative to parenteral administration, but its effectiveness has not been definitively demonstrated. The following protocol was designed to compare the effectiveness of orally and intramuscularly administered vitamin B12 in the treatment of patients $\geq 65$ years of age with vitamin B12 deficiency.
\end{abstract}

Methods/design: The proposed study involves a controlled, randomised, multicentre, parallel, non-inferiority clinical trial lasting one year, involving 23 primary healthcare centres in the Madrid region (Spain), and patients $\geq 65$ years of age. The minimum number of patients required for the study was calculated as 320 (160 in each arm). Bearing in mind an estimated 8-10\% prevalence of vitamin B12 deficiency among the population of this age group, an initial sample of 3556 patients will need to be recruited.

Eligible patients will be randomly assigned to one of the two treatment arms. In the intramuscular treatment arm, vitamin B12 will be administered as follows: $1 \mathrm{mg}$ on alternate days in weeks 1 and 2, 1 mg/week in weeks 3-8,and $1 \mathrm{mg} / \mathrm{month}$ in weeks 9-52. In the oral arm, the vitamin will be administered as: $1 \mathrm{mg} /$ day in weeks 1-8 and 1 $\mathrm{mg} /$ week in weeks 9-52. The main outcome variable to be monitored in both treatment arms is the normalisation of the serum vitamin B12 concentration at weeks 8, 26 and 52; the secondary outcome variables include the serum concentration of vitamin B12 (in pg/ml), adherence to treatment, quality of life (EuroQoL-5D questionnaire), patient

\footnotetext{
* Correspondence: teresa.sanzcu@salud.madrid.org

${ }^{1}$ Unidad de Apoyo a la Investigación. Gerencia Atención Primaria, Servicio

Madrileño de Salud, Calle Espronceda 24, Madrid 28003, Spain

Full list of author information is available at the end of the article
} 


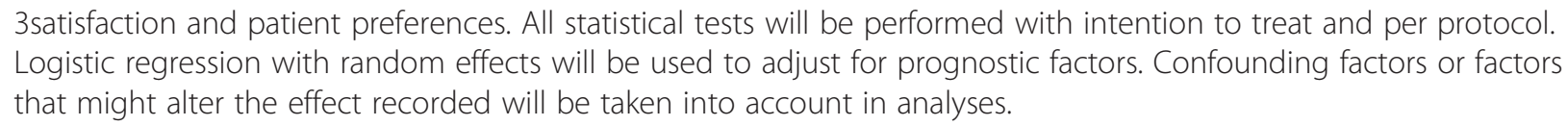

Discussion: The results of this study should help establish, taking quality of life into account, whether the oral administration of vitamin B12 is an effective alternative to its intramuscular administration. If this administration route is effective, it should provide a cheaper means of treating vitamin B12 deficiency while inducing fewer adverse effects. Having such an alternative would also allow patient preferences to be taken into consideration at the time of prescribing treatment.

Trial registration: This trial has been registered with ClinicalTrials.gov, number NCT 01476007, and under EUDRACT number 2010-024129-20.

\section{Background}

Vitamin B12 (cyanocobalamin), along with other derivatives of folic acid, is a nutrient essential for the synthesis of DNA. Its deficiency is manifested through changes in the number and morphology of erythrocytes, leucocytes and platelets, and by neurological alterations owed to the progressive demineralisation of the nervous system (a consequence of defective myelin synthesis). Vitamin B12 is found mostly in food of animal origin. It is separated from ingested food through the action of the gastric acid, and in the duodenum the vast majority binds to intrinsic factor (IF). The vitamin B12/IF complex formed, which is very resistant to digestion, is then absorbed by endocytosis in the terminal ileum. Only $1-2 \%$ of vitamin B12 absorption occurs independent of IF [1]. Daily vitamin B12 requirements vary between 1 and $2 \mu \mathrm{g} /$ day in adults [2]. A balanced diet, however, provides somewhere between 7 and $30 \mu \mathrm{g} /$ day. Some of this excess can be stored (some $2-5 \mathrm{mg}$ ), meaning that deficiency symptoms may not occur until 3-5 years after the diet fails to provide sufficient vitamin $\mathrm{B} 12$ or its absorption becomes inadequate [3].

In the primary healthcare setting, the most commonly seen causes of vitamin B12 deficiency are related to abnormalities of digestion (atrophic gastritis, achlorhydria or the consequences of gastrectomy) or absorption (autoimmune pernicious anaemia, chronic pancreatitis, Crohn's disease, the effect of medications that alter the mucosa of the ileum, or the consequences of surgical resection), and, to a lesser extent, a lack of exogenous supply. The exact prevalence of vitamin B12 deficiency in industrialised countries is unknown; indeed, different studies using different definitions have reported it as between 5\% and 60\% [4]. Results have even differed widely between similar studies using an identical definition of deficiency, and after stratifying by age [5]. In Spain, the prevalence of vitamin B12 deficiency may reach 18\% according to a meta-analysis of the studies undertaken up to 1999 [6]. However, population-based studies performed in Catalonia and the Canary Islands $[7,8]$, both of which used a serum vitamin B12 cut-off of $200 \mathrm{pg} / \mathrm{ml}$, returned values of $1.9 \%$ and $3.4 \%$ respectively. What does appear to be constant in all studies reviewed for the present work is that the prevalence of deficiency is greater among people aged 65-76 years. For example, the above Catalonian and Canary Island studies returned values of $3.8 \%$ and $8.5 \%$ for these age groups. Among elderly patients belonging to the Framingham cohort, Lidenbaun [9] observed a prevalence of over $5.3 \%$. Other authors $[10,11]$, however, report figures of $30-40 \%$ in elderly people with degenerative neuropsychiatric disorders and those receiving institutionalised care.

In the elderly, the symptoms of vitamin B12 deficiency caused by deficient diets and/or digestive and/or absorption problems can be nonspecific, making a diagnosis of deficiency more difficult. For example, up to $40 \%$ of elderly people show no haematological alterations. Further, neurological symptoms may appear before those of anaemia; indeed, only about $60 \%$ of elderly people with vitamin B12 deficiency are anaemic [12].

In primary healthcare in Spain, vitamin B12 deficiency is diagnosed via the determination of the serum concentration of the vitamin. Some studies [13-17] have described the limitations of trying to diagnose vitamin B12 deficiency exclusively via the measurement of this concentration, and report blood methylmalonic acid (MMA) and homocysteine concentrations to be more sensitive markers capable of detecting subclinical deficiency.

The traditional treatment of vitamin B12 deficiency is the intramuscular injection of cyanocobalamin, generally $1 \mathrm{mg} /$ day for one week, followed by $1 \mathrm{mg} /$ week for one month, and then $1 \mathrm{mg}$ every 1 or 2 months ad perpetuum $[4,18,19]$. The vitamin may, however, be offered orally. In some circles this route has been regarded as an effective alternative to parenteral administration since the 1950s, during which time several studies showed serum vitamin B12 concentration to normalise after taking large oral doses. These results prompted the spread of oral administration in Sweden and Canada [3]. In the former country, $13 \%$ of the population over 70 years of age 
now receives treatment for vitamin B12 deficiency, with two of every three patients treated via the oral route [20]. However, in the rest of the world, the parenteral route remains the most used. Indeed, controversy still surrounds the advantages and effectiveness of the oral route. Some authors question its use [21] while others favour it, although the methodological limitations of the evidence they provide means no firm conclusions can be drawn. In reviews of the literature published between 1999 and 2007, Daly-Youcef [4] and Andrés E [19] concluded that orally administered vitamin B12 provided effective treatment for adult and elderly patients with deficiencies, although they highlighted that further studies were needed to determine its effectiveness in patients with severe neurological symptoms. Federicia [22], who reviewed the treatment criteria followed in different studies, concluded oral administration to be effective, but recommended further work to confirm this. Shatsky[23], who examined evidence derived from the use of oral and intramuscular administration, indicated that high dose oral administration appeared to be safe, effective and cost-effective, although long term clinical trials were required to confirm this. In a prospective study performed in Spain involving commercially available multi-vitamin supplements, Rabuñal et al. [24] reported the effectiveness and tolerance of oral vitamin $\mathrm{B} 12$ to be excellent, but also indicated that the dosage to be used was yet to fully established. In 2005, a Cochrane review [3] was published that examined two randomised clinical trials - those reported by Kuzminski [2] and Bolaman [25] - that studied the effectiveness of oral vs. intramuscular administration of vitamin B12 for the treatment of its deficiency. The Kuzminski trial involved 33 patients (18 in the oral arm and 15 in the intramuscular arm), while the Bolaman trial involved 60 (26 in the oral arm and 15 in the intramuscular arm). The Cochrane concluded that orally administered vitamin B12 appeared to be as effective as the intramuscular route with respect to the short-term haematological and neurological responses observed in patients with deficiencies, but highlighted methodological limitations in both trials. A large clinical trial was called for in the primary healthcare setting, where a high percentage of patients with vitamin B12 deficiency is seen. The Cochrane review also underscored the need to include a measurement of the quality of life as an outcome, and patient preference at the time of prescribing treatment. Among other variables, three studies $[24,26,27]$ have recorded patient views on the administration route, and record a high level of acceptance of the oral route, the advantages of which include avoiding the displacement of patients to receive injections, avoiding the discomfort of injection, and a reduction in treatment costs $[28,29]$.

A further question still to be answered is that of the optimum dose when using the oral route [3].

In summary, despite many studies indicating the oral administration of vitamin B12 to be easy, effective and less costly than intramuscular administration, their designs, and in some cases their methodological limitations, mean that debate still surrounds the effectiveness of the oral route. This may help explain why it is little used by health professionals [30].

Although some authors [31,32] recommend the use of moderately high doses (which have obtained the best results), studies are still being performed to investigate this. In a randomised clinical trial involving five treatment arms with doses of between $2.5 \mu \mathrm{g} /$ day and $1000 \mu \mathrm{g} /$ day, Eussen [33] concluded that a dose of at least $600 \mu \mathrm{g} /$ day was required to obtain adequate results. However, in guidelines published in 2012, the British Columbia Medical Association (Canadian Ministry of Health) recommended a dose of $1000 \mu \mathrm{g} /$ day for pernicious anemia or food-bound cobalamin malabsorption [34].

The proposed study examines the questions that, according to the Cochrane review mentioned above [3], are still to be answered, via a clinical trial (of ample duration and with a large number of patients) in the primary healthcare setting. As recommended, one of the outcomes examined is quality of life. The results obtained should provide high quality scientific evidence of use when taking treatment decisions in the primary healthcare centres, while allowing patient preference of administration route to be taken into consideration. The results may reveal oral treatment with vitamin B12 to be, as Lederle [35] put it, "medicine's best kept secret".

\section{Aim}

The aim of the proposed protocol is to compare the effectiveness of orally and intramuscularly administered vitamin B12 in the normalisation of serum vitamin B12 concentrations at 8,26 and 52 weeks of treatment, in patients aged $\geq 65$ years with vitamin B12 deficiency treated at primary healthcare centres in the Madrid region, Spain. The secondary outcomes to be measured include the safety of both administration routes, quality of life (measured using the EuroQoL-5D questionnaire) and adherence to treatment. Patient preferences and satisfaction with treatment will also be recorded, along with patient sociodemographic profiles, lifestyle habits, and the clinical manifestation of each patient's deficiency.

\section{Methods/design Study type}

This study takes the form a pragmatic, randomised, multicentre, non-inferiority clinical trial undertaken in the 
primary healthcare setting, with a duration of one year. For ethical reasons, a placebo controlled trial would not be appropriate [36].

The study involves 23 primary healthcare centres in the Madrid region of Spain. The research team is composed of a clinical assistance group of 169 general practitioners and nurses, and a technical group of 22 health professionals including doctors of different specialities, nurses and pharmacists. For the undertaking of fieldwork, these 191 team members are divided into smaller groups (with similar numbers of clinical and technical personnel), each in charge of one of five subprojects. Each subproject is led by a member of the technical personnel. Together, these five leaders form the coordination group for the trial as a whole.

The trial protocol was approved by the Madrid Region Clinical Research Ethics Committee (Comité Ético de Investigación Clínica Regional de la Comunidad de Madrid) on February $8^{\text {th }}$ 2011, and has been registered with ClinicalTrials.gov number NCT 01476007, and under EUDRACT number 2010-024129-20 [Oral Versus Intramuscular Cobalamin to treat Cobalamin Deficiency: Noninferiority randomised controlled trial, pragmatic and multi-center in the primary healthcare setting (OB12 project)].

\section{Patients}

1. Inclusion criteria: all participants must:

- be $\geq 65$ years of age

- be attending a primary healthcare centre for consultation on some medical matter

- provide their informed consent to be included

- have a serum B12 concentration of $<179 \mathrm{pg} / \mathrm{ml}$.

2. Exclusion criteria: patients meeting any of the following conditions will be excluded:

- having been treated (under medical prescription) in the last five years for vitamin B12 deficiency

- serious neurological or psychiatric symptoms, including psychotic problems

- dementia preventing the giving of informed consent to take part

- atrophy of the optic nerve

- serum folic acid concentration of $<2.3 \mathrm{ng} / \mathrm{ml}$

- stage 4 kidney disease 4 (estimated glomerular filtration rate [GFR] $15-29 \mathrm{ml} / \mathrm{min}$ )

- having received/suffering malabsorption-related: O surgery or diseases affecting the jejunum-ileum O inflammatory-intestinal disease, e.g., Crohn's disease, ulcerative colitis

$O$ celiac disease

- chronic pancreatitis

- myelodisplasia or malignant blood disease

- haemophilia or other coagulation problems contraindicating parenteral administration
- severe systemic disease

- having been involved in any other trial involving the administration of any experimental treatment in the 28 days prior to the start of the present study

- being treated for HIV, HVB or HVC infection

- hypersensitivity to vitamin B12, or any of the vitamin preparation's excipients

- receiving anticoagulation treatment

- being away from home and with no intention of residing for the following year in the health district where consultation was made

- failing to meet any inclusion criterion

- limitations regarding oral treatment

\section{Randomisation}

Participants will be enrolled consecutively by their general practitioners when attending a primary healthcare centre in the study area (Figure 1). All patients without reason to be excluded will be invited to participate. Those patients that accept this invitation will provide written, informed consent to be included. A blood sample will then be taken and part of this used to determine the serum vitamin B12 concentration ( $\mathrm{pg} / \mathrm{ml})$. In those returning a value of $<179 \mathrm{pg} / \mathrm{ml}$ (defined as vitamin B12 deficiency by the reference analytical laboratory analysing the samples collected), the remaining fraction of the sample will be analysed to provide a haemogram (reticulocyte, erythrocyte, leucocyte and platelets counts), the values of biochemical variables (glucose, creatinine, GOT, GPT, GGT and ferritin), the folic acid concentration, and an anti-IF antibody count. Those who meet all inclusion criteria, and no exclusion criteria, will then be randomly assigned to one arm of the treatment, i.e., oral or intramuscular administration of vitamin B12. This will be performed by means of a simple randomisation process performed by the electronic data collection system. This guarantees that neither researcher nor patient has any choice with respect to the group to which the latter is assigned.

\section{Sample size}

The sample size required was determined bearing in mind the results of Kuzminski et al. [2]. In the latter study the parenteral administration of vitamin B12 was associated with an increase in serum concentrations of the vitamin of $>200 \mathrm{pg} / \mathrm{ml}$ at 4 months in over $70 \%$ of patients. For the present trial, the level of non-inferiority of the oral treatment is set at a difference (delta) in response compared to the parenteral treatment of $\leq 10 \%$. This threshold was set given its importance from a clinical rather than a statistical viewpoint, and since it falls within the range normally accepted for this type of study [37]. 


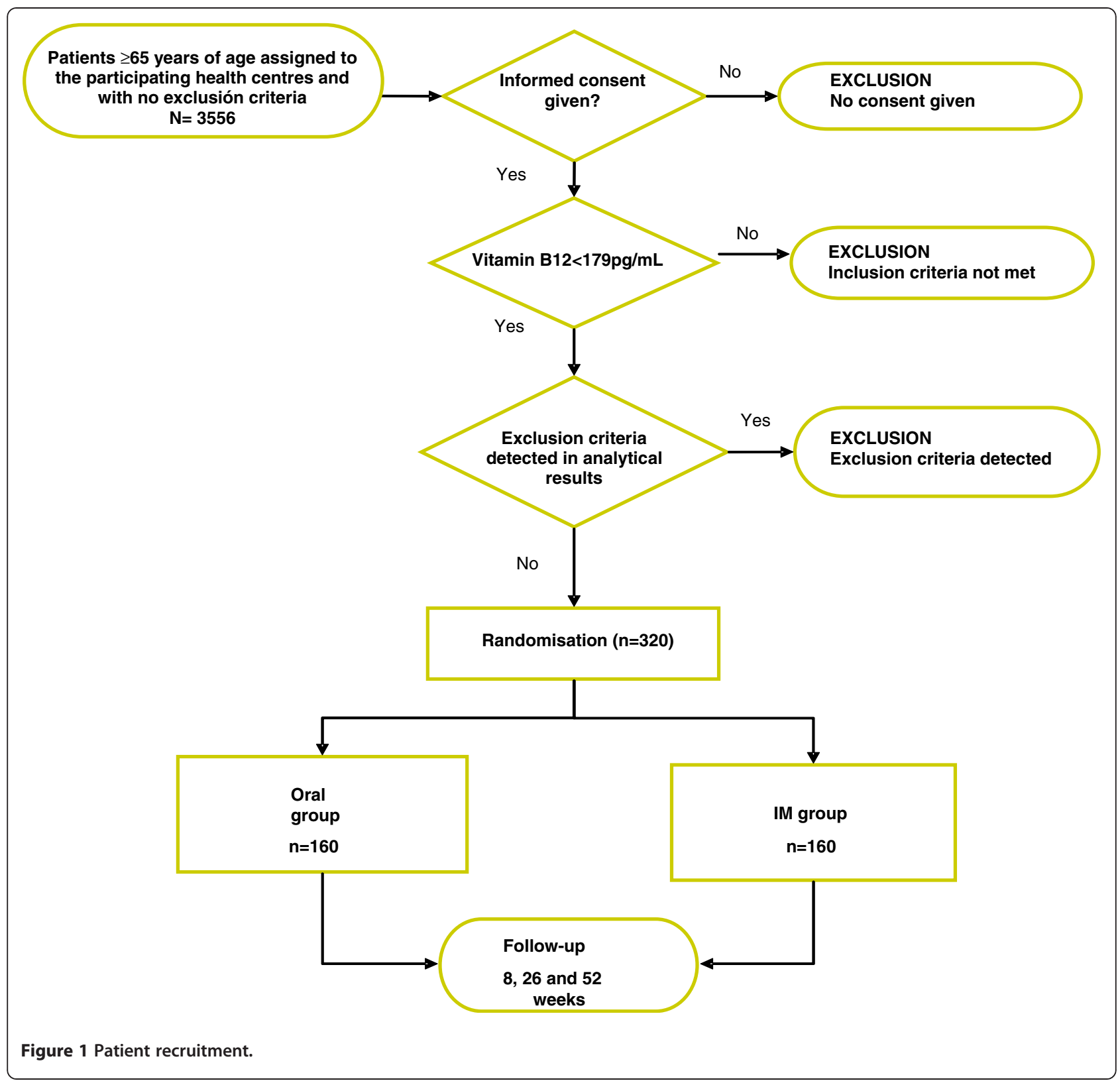

Assuming that the percentage of patients showing an increase in serum vitamin B12 concentration to above $179 \mathrm{pg} / \mathrm{ml}$ in both groups is $70 \%$, means the study requires at least 304 patients (152 in each arm) for a threshold of non-inferiority of $10 \%$ and a statistical power of $60 \%$ with significance set at $\mathrm{p}<0.05$. Given the type of patients to be studied, i.e., patients who have come to the health centres for consultation, plus the fact that their own family doctors are members of the research team, a loss to follow-up of under $5 \%$ is expected. The minimum starting sample size for each arm was therefore deemed to be $\mathrm{n}=160$. With an expected prevalence of vitamin B12 deficiency of $8-10 \%$ (a figure of 9\% was used in calculations), the original number of patients to be enrolled so that 320 with a vitamin B12 deficiency can be guaranteed is 3556 .

\section{Blinding}

In studies with the present design it is impossible to blind the patient to the treatment received. However, this limitation is compensated for by the objective measurement of the main outcome variable (the serum vitamin B12 concentration) and the randomisation of the patients to the treatment groups. Further, the persons charged with the statistical analysis of the data will be blind to the identity of the patients in each treatment arm. 


\section{The intervention}

The pharmaceutical formulations to be used in the study are commercially available in Spain. The treatments will involve:

- Intramuscular route: $1 \mathrm{mg}$ of vitamin B12 on alternate days during weeks 1 and 2; $1 \mathrm{mg} /$ week over weeks 3-8 (i.e., for 6 weeks); and $1 \mathrm{mg} / \mathrm{month}$ from weeks 9-52

- Oral route: $1 \mathrm{mg} /$ day of vitamin B12 for 8 weeks; $1 \mathrm{mg} /$ week from weeks 9-52

Patients in both arms will undergo analytical monitoring in weeks 8, 26 and 52. They will receive appointments for the appropriate dates. The response to treatment will be recorded alongside adherence to treatment and the appearance of any adverse effects.

\section{Work plan}

Before work begins, the project will be presented to all the research team members in a special meeting. Training sessions lasting 2-3 h will also be held at each participating health centre. These will involve a review of the inclusion and exclusion criteria, provide instructions regarding the intervention, and examine the ethical requirements to be met for the trial to be held.

The procedures to be followed and information to be recorded at each of a patient's visits to a participating health centre is as follows:

\section{- Selection Visit}

- Signing of informed consent

- Assessment of inclusion/exclusion criteria

- Recording of demographic data (age and sex)

- Analysis: serum vitamin B12. If concentration is $<179 \mathrm{pg} / \mathrm{ml}$ the following analyses are to be requested: haemogram, biochemical analysis (glucose, creatinine, GOT/GPT/GGT), ferritin, folic acid, anti-IF antibody level. If serum vitamin B12 concentration is $>179 \mathrm{pg} / \mathrm{ml}$ : patient preference questionnaire

- Randomisation of patients to treatment group

- Visit 1 (start of treatment)

- Anamnesis: record whether the patient lives alone or with others, lifestyle habits, use of alcohol, whether a vegan diet is followed, whether the patient has undergone gastrectomy

- Symptoms: record paresthesia, asthenia, loss or reduction of appetite, sadness or change in state of mind, concomitant pharmacological treatment

- Physical examination: for Hunter's glositis, positional and vibrational sensitivity

- Questionnaires: Lobo cognitive mini-exam, EuroQoL-5D

- Record concomitant treatment
- Request analyses to be performed one week before next visit: haemogram and serum vitamin B12

- Therapeutic plan: patient in oral arm - provision of medication; patient in intramuscular arm provide appointments for injections

- Visit 2 (week 8)

- Anamnesis: record lifestyle habits and use of alcohol

- Symptoms: if pathological at the first visit, record paresthesia, asthenia, loss or reduction of appetite, sadness or change in level of happiness, and concomitant pharmacological treatment

- Physical examination: if pathological at the first visit examine for Hunter's glositis, positional and vibrational sensitivity

- Record concomitant treatment

- Request analyses to be performed one week before next visit: haemogram and serum vitamin B12

- Questionnaires: EuroQoL-5D

- Assessment of adverse effects

- Therapeutic plan: patient in oral arm - provision of medication; patient in intramuscular arm provide appointments for injections

- Assess adherence to treatment: oral route count number of vials used; intramuscular route: count injections given

- Visit 3 (week 26)

- Anamnesis: record lifestyle habits and use of alcohol

- Symptoms: if pathological at the first visit, record paresthesia, asthenia, loss or reduction of appetite, sadness or change in level of happiness, and concomitant pharmacological treatment

- Physical examination: if pathological at the first visit examine for Hunter's glositis, positional and vibrational sensitivity

- Record concomitant treatment

- Request analyses to be performed one week before next visit: haemogram and serum vitamin B12

- Questionnaire: EuroQoL-5D

- Assessment of adverse effects

- Therapeutic plan: patient in oral arm - provision of medication; patient in intramuscular arm provide appointments for injections

- Assess adherence to treatment: oral route count number of vials used; intramuscular route: count injections given

- Visit 4 (week 52)

- Anamnesis: record lifestyle habits and use of alcohol 
- Symptoms: record paresthesia, asthenia, loss or reduction of appetite, sadness or change in level of happiness, and concomitant pharmacological treatment

- Physical examination: for Hunter's glositis, positional and vibrational sensitivity

- Record concomitant treatment

- Questionnaires: EuroQoL-5D, satisfaction and preferences

- Assessment of haemogram and serum vitamin B12 concentration

- Assessment of adverse effects

- Assess adherence to treatment: oral route count number of vials used; intramuscular route: count injections given

\section{Variables}

\section{Outcome variables}

The main outcome to be measured is the normalisation of the serum vitamin B12 concentration $(>179 \mathrm{pg} / \mathrm{ml})$ at 8,26 and 52 weeks. The secondary outcomes will be the serum vitamin B12 concentration ( $\mathrm{pg} / \mathrm{ml})$, adverse events (description, moment of onset and resolution, intensity, cause, steps taken), adherence to treatment (measured at each patient visit via the number of vials used for patients in the oral arm, and the number of injections given in the intramuscular arm), quality of life (measured using the EuroQoL-5D questionnaire), and patient satisfaction and preferences.

\section{Anamnesis, demographic and lifestyle information} Including age, sex, whether the patient lives alone or with others, whether a vegan diet is followed, and the use of alcohol (g/week).

\section{Clinical variables}

Symptoms such as paresthesia, asthenia, loss or reduction of appetite, sadness or change in state of mind (anamnesis), Hunter's glositis, positional and vibrational sensitivity (all via physical examination), and cognitive decline (Lobo test).

\section{Analytical variables}

Haemogram (complete blood cell and platelet count) and biochemical analysis (folic acid, glucose, creatinine, GOT, GPT, GGT, ferritin, anti-IF antibodies). Blood analyses will be performed in plasma or serum as required and under standard conditions.

\section{Concomitant treatment}

Recording of the taking of protein pump inhibitors, H2 receptor antagonists, antacids, potassium, metformin, colchicine, neomycin, p-aminosalicylic acid, parenteral chloramphenicol, $\mathrm{Fe}$, vitamin $\mathrm{C}$ and other vitamin supplements.

\section{Losses and withdrawals}

Patients will be removed from the trial if any of the following conditions are met:

- Serum vitamin B12 concentration still $<179 \mathrm{pg} / \mathrm{ml}$ after 8 weeks of treatment. Treatment will be deemed to have failed in these patients, and they will be further studied and treated outside the trial according to normal clinical practice.

- Serious adverse events.

- Voluntary withdrawal or violation of the protocol.

At least two attempts will be made to contact by telephone those patients who do not come for their scheduled visits. All patients will be informed that they can abandon the study at any time without this affecting their future medical treatment in any way.

\section{Analysis}

\section{Descriptive analysis of the patients}

The trial will involve a descriptive statistical analysis of the baseline characteristics of patients in both treatment arms. Quantitative variables will be described in terms of their measure of central tendency, mean or median (for those showing asymmetric distributions), and the corresponding dispersion, standard deviation or interquartile range. Qualitative variables will be described in terms of proportions and their corresponding confidence intervals.

\section{Baseline comparisons}

The Student $\mathrm{t}$ test or Mann-Whitney $\mathrm{U}$ test (when the normal hypothesis is rejected) will be used to determine whether the two treatment arms are comparable based on their quantitative baseline characteristics and known prognostic factors. Comparisons on qualitative variables will be undertaken using the Pearson Chi-squared test or Fisher's Exact test as required. If cases of inequality are detected, the confounding factors will be defined and appropriate adjustments made.

\section{Analysis of effectiveness of treatment (main outcome) at the three monitoring points}

Intention-to-treat and per-protocol analyses will both be performed, as is recommended for non-inferiority studies [38].

The effectiveness of treatment will be analysed by examining the therapeutic success achieved in each arm at 8,26 and 52 weeks, determining the $95 \%$ confidence interval for the percentage of patients in each treatment arm whose serum vitamin B12 concentrations become normalised. If the confidence intervals do not fall outside the non-inferiority limit (10\%), it can be concluded that 
the oral treatment is not inferior to the intramuscular treatment. The within-patient percentage change in serum vitamin B12 concentration at each monitoring point will be determined, and the confidence intervals for the difference in the mean values for each arm calculated.

If the distribution of confounding factors differs in the two arms, explicative regression analysis will be performed in which the dependent variable will be the normalisation of the serum vitamin B12 concentration, and the independent variable will be the treatment group.

Repeated measures ANOVA will be used to examine the change in serum vitamin B12 concentration in each group at each monitoring point.

\section{Safety analysis}

The incidence of adverse events in the two arms will be compared using the Pearson Chi-squared test or Fisher's Exact test as required.

\section{Quality of life analysis}

The perception of quality of life by the patients of each arm will be assessed by comparing the EuroQol 5D scores (determined using a visual analogue scale) and the transformation of these scores into utility-based quality of life values.

\section{Analysis of adherence to treatment}

Adherence to treatment will be examined via the counting of oral doses taken in the oral arm, and the number of injections given in the intramuscular arm. An operative indicator variable will then be defined to describe the degree of adherence.

\section{Ethics}

The trial has been approved by the Madrid Region Clinical Research Ethics Committee (February $8^{\text {th }}$ 2011). It will be performed by qualified medical and scientific staff. The rights and welfare of the patients will be respected at all times. All patients will be adequately informed, both verbally and in writing, of the nature of the trial, its aim, and its risks and possible benefits. Given that the study is a non-inferiority trial, all patients will be informed that the oral treatment is expected to be as effective as the standard intramuscular treatment. Signed, dated consent to be included will be required from each patient.

Spanish law regarding the use of human subjects in clinical trials will be adhered to. The trial will respect all basic ethical principles of autonomy, justice, goodness of intent and absence of malintent according to the standards of good clinical practice enshrined in the Declaration of Helsinki (Seoul, 2008) and the Oviedo Agreement (Convenio de Oviedo) (1997).

\section{Discussion}

From a clinical point of view, the results obtained will help establish whether the oral administration of vitamin B12 is as effective as intramuscular treatment in the normalisation of serum vitamin B12 concentrations in patients $\geq 65$ years of age with a deficiency. Knowledge in this respect is important since oral administration should provide these patients with greater autonomy, improve patient satisfaction with treatment, and reduce treatment costs. Patients receiving anti-coagulation treatment, for whom intramuscular treatment may be contraindicated, should also benefit. The possibility of taking an oral preparation would also allow patient preferences to be taken into account when deciding on what treatment to prescribe; indeed, patient preference is a factor of prime importance in clinical decision-taking. The possibility of providing treatment options in normal clinical practice rests on two conditions being met: 1) that quality scientific information supports the effectiveness of the therapeutic options on offer, and 2) that heterogeneous groups of patients have recorded their satisfaction with these options. The present trial provides for information in this respect to be gathered [39] and therefore treatment preferences to be taken into account at the time of prescription.

The trial is also designed to provide information on the effect of the normalisation of serum vitamin B12 concentrations by both treatments on patient-perceived quality of life. Physicians commonly assume that taking oral supplements will be associated with a feeling of greater well-being, although this has never been proven [40]. The present trial should also throw light on this.

The trial suffers from the practical limitation of having to enrol a large number of patients to meet its sample size requirements. However, a high degree of motivation is expected of the research team since its clinical assistance members are those involved in the enrolment process. Further, the fact that the patients to be enrolled will be seeking medical help (although not necessarily for vitamin B12 deficiency) suggests few will be lost to follow-up. A further possible limitation is the low statistical power used in the calculation of the sample size. The $60 \%$ power contemplated requires a sample size of 304 patients (152 in each arm) - higher powers would increase the sample size required and the enrolment of such numbers cannot be guaranteed. However, given the results reported in previous studies $(2,25,31-33)$ that used moderate/high doses of vitamin B12, it should be possible to demonstrate the noninferiority of the oral treatment with this power level. If the $95 \%$ confidence interval were to cross the non-inferiority threshold, i.e., showing the results to be inconclusive, the intramuscular treatment would remain the treatment of choice. To determine the degree of adherence to treatment (and thus avoid outcome dilution effects) [41], the 
number of doses taken orally and received by injection will be recorded. The characteristics of all the original 320 patients will be recorded to provide insight into the type of patient left in the study after any withdrawals, as recommended by the CONSORT group [41,42]. Basic information (age, sex, etc.) on potentially eligible patients who decline to take part will also be recorded. This type of information is of use when assessing the possible extrapolation of the trial results to more general populations.

The decision not to take serum methylnalonic acid and homocysteine concentrations into account as diagnostic markers and outcome variables was made bearing in mind that these are not normally determined, either at diagnosis or during follow-up, in patients with a vitamin B12 deficiency.

Finally, given the pragmatic nature of the proposed trial, the decision was taken to include consecutive patients seeking medical help at the participating centres, thus ensuring the enrolment of subjects similar to those that would be seen in normal clinical practice.

\section{Abbreviations \\ Fe: Ferrum; g: Gram; GFR: Glomerular filtration rate; GGT: Gamma-glutamyl transpeptidase; GOT: Glutamic oxaloacetic transaminase; GP: General practitioner; GPT: Glutamic-pyruvic transaminase; HIV: Human immunodeficiency virus; HVB: Hepatitis B virus; HVC: Hepatitis C virus; IF: Intrinsic factor; $\mu \mathrm{g}$ : Microgram; MMA: Methylmalonic acid; mg: Milligrams; ng: Nanograms; pg: Picograms.}

\section{Competing interests}

The authors declare that they have no competing interests.

\section{Author details}

${ }^{1}$ Unidad de Apoyo a la Investigación. Gerencia Atención Primaria, Servicio Madrileño de Salud, Calle Espronceda 24, Madrid 28003, Spain. ${ }^{2}$ Centro de Salud Buenos Aires. Dirección Asistencial Sureste. Gerencia Atención Primaria. Servicio Madrileño de Salud, Calle Pío Felipe s/n, Madrid28038, Spain. ${ }^{3}$ Unidad de Apoyo a la Investigación. Unidad Docente Multiprofesional (UDM) Atención Familiar y Comunitaria Sur. Gerencia Atención Primaria, Servicio Madrileño de Salud, Avenida Juan de la Cierva s/n, Getafe28902, Spain. ${ }^{4}$ Unidad de Apoyo a la Investigación. UDM Atención Familiar y Comunitaria Sureste. Gerencia Atención Primaria, Calle Hacienda de Pavones 271, Madrid28030, Spain. ${ }^{5}$ Unidad de Apoyo a la Investigación. Gerencia Atención Primaria, Servicio Madrileño de Salud, Calle Espronceda 24, Madrid28003, Spain. ${ }^{6}$ UDM Atención Familiar y Comunitaria Oeste. Unidad de Apoyo a la Investigación. Gerencia Atención Primaria. Servicio Madrileño de Salud, Calle Alonso Cano 8, Móstoles28933, Spain. ${ }^{7}$ Unidad de Apoyo a la Investigación. Gerencia Atención Primaria, Servicio Madrileño de Salud, Calle Espronceda 24, Madrid28003, Spain. ${ }^{8}$ Hospital Universitario La Princesa. Servicio Madrileño de Salud, Calle Diego de León 62, Madrid28006, Spain. ${ }^{9}$ Dirección General de Sistemas de Información. Consejería de Sanidad, Comunidad de Madrid, Calle Julián Camarillo 4B 1, Madrid28037, Spain. ${ }^{10}$ CAIBER-Spanish Clinical Research Network. UCICEC Agencia Laín Entralgo, Calle Gran Vía 27, Madrid28013, Spain. ${ }^{11}$ CAIBER-Spanish Clinical Research Network. UCICEC Agencia Laín Entralgo, Calle Gran Vía 27, Madrid28013, Spain. ${ }^{12}$ Hospital Universitario Gregorio Marañón. Servicio Madrileño de Salud, Calle Dr. Esquerdo 46, Madrid28007, Spain. ${ }^{13}$ Servicio de Farmacia. Dirección Asistencial Sureste. Gerencia Atención Primaria. Servicio Madrileño de Salud, Calle Hacienda de Pavones 271, Madrid28030, Spain. ${ }^{14}$ Servicio de Farmacia. Dirección Asistencial Sureste. Gerencia Atención Primaria. Servicio Madrileño de Salud, Calle Hacienda de Pavones 271, Madrid28030, Spain. ${ }^{15}$ Servicio de Farmacia. Dirección Asistencial Sur. Gerencia Atención Primaria. Servicio Madrileño de Salud, Avenida Juan de la Cierva s/n, Getafe28902, Spain. ${ }^{16}$ Unidad de Medicina Preventiva, Hospital de Denia, Marina Salud, Agéncia Valenciana de Salut, Partida de Beniadlá, s/n, Dénia03700, Spain.
${ }^{17}$ Centro de Salud Centro de Salud Mendiguchia Carriche Gerencia de Atención Primaria. Servicio Madrileño de Salud, Calle Comunidad de Madrid s/n, Leganés28912, Spain. ${ }^{18}$ Centro de Salud El Greco. Gerencia de Atención Primaria. Servicio Madrileño de Salud, Calle Avda. Reyes Católicos s/n, Getafe28904, Spain. ${ }^{19}$ Unidad de Apoyo Técnico. Unidad de Apoyo a la Investigación. Gerencia Atención Primaria. Servicio Madrileño de Salud, Calle O'Donnell 55, Madrid28009, Spain. ${ }^{20}$ UDM Atención Familiar y Comunitaria Oeste. Unidad de Apoyo a la Investigación. Gerencia Atención Primaria. Servicio Madrileño de Salud, Calle Alonso Cano 8, Móstoles28933, Spain.

${ }^{21}$ Unidad Docente Multiprofesional Noroeste. Unidad de Apoyo a la Investigación. Gerencia Atención Primaria. Servicio Madrileño de Salud, Avda. de España, 7 - 3 planta, Majadahonda28220, Spain. ${ }^{22}$ UDM Atención Familiar y Comunitaria Norte. Unidad de Apoyo a la Investigación. Gerencia Atención Primaria. Servicio Madrileño de Salud, Calle Melchor Fernández Almagro, 1., Madrid28029, Spain. ${ }^{23}$ Unidad de Apoyo a la Investigación. Gerencia Atención Primaria, Servicio Madrileño de Salud, Calle Espronceda 24, Madrid28003, Spain. ${ }^{24}$ Centro de Salud M Ángeles López Gómez. Gerencia de Atención Primaria. Servicio Madrileño de Salud, Calle María Ángeles López Gómez 2, Leganés28915, Spain. ${ }^{25}$ Unidad de Apoyo Técnico. Unidad de Apoyo a la Investigación. Gerencia Atención Primaria. Servicio Madrileño de Salud, Calle O'Donnell 55, Madrid28009, Spain. ${ }^{26}$ Unidad de Apoyo a la Investigación. Unidad Docente Multiprofesional Sur. Gerencia Atención Primaria, Servicio Madrileño de Salud, Avenida Juan de la Cierva $s / n$, Getafe28902, Spain. ${ }^{27}$ Servicio de Hematología. Hospital Severo Ochoa. Servicio Madrileño de Salud, Avenida de Orellana s/n, Leganés28911, Spain. ${ }^{28}$ Servicio de Endocrinología. Hospital Universitario Gregorio Marañón. Servicio Madrileño de Salud, Calle Dr. Esquerdo 46, Madrid28007, Spain. ${ }^{29}$ Dirección General de Atención al Paciente. Servicio Madrileño de Salud, Plaza Carlos Trías Bertrán 7, Madrid28020, Spain. ${ }^{30}$ Hospital Universitario clínico San Carlos. Servicio Madrileño de Salud, Calle Profesor Martín Lagos s/ n, Madrid28040, Spain. ${ }^{31}$ Profesor Asociado de Ciencias de la Salud. Departamento de Medicina. Facultad de Medicina. Universidad Complutense de Madrid. Centro de Salud Guayaba. Dirección Asistencial Centro, Calle Antonia Rodríguez Sacristán 4, Madrid20044, Spain. ${ }^{32}$ Dirección Técnica de Procesos y Calidad. Gerencia Atención Primaria. Servicio Madrileño de Salud, Calle Doctor Cirajas 20, Madrid28017, Spain. ${ }^{33}$ Universidad de Alcalá, Facultad de Medicina, Campus Universitario, Ctra. Madrid-Barcelona Km 33,600., Alcalá de Henares28871, Spain. ${ }^{34}$ Gerencia Atención Primaria, Servicio Madrileño de Salud, Madrid, Spain.

\section{Authors' contributions}

PGE y RRF conceived of the study and participated in its design. TSC; RRF; SGE; IdCG; JMF; EEM; participated in the design and coordination of the study. FRS; MGS; RGG; MAMS; COL; MLSP; CMR; BMB; AVP; FGBG; JEMS; RRB; GAC; LMCB; EPC; MRB; MTRM; SSD; SMI; RRG; IBL; MVN; JSD; TGG; MDC; AAB participated in different phases of the design. TSC; RRF; SGE; IdCG; JMF; EEM directed the writing of the manuscript. All authors OB12 Group read and approved the final manuscript.

\section{Funding}

This study was funded by the Ministerio de Sanidad, Politica Social e lgualdad, Spain (EC10-115, EC10-116, EC10-117, EC10-119, EC10-122) and by CAIBER Spanish Clinical Research Network. The authors thank the following persons for their contributions to this work: Dolores Otero-Criado, Carlos Carvajales Fernández, Rosa Zurdo-Baz and Raisa González-Pérez.

\section{The OB12 Group}

Healthcare Centre (HC) Barajasx: Germán Reviriego Jaén, Cristina Montero García, Ana Isabel Sanz Lorente, Ma del Pilar Serrano Simarro, Julián Díaz Sánchez, Irma M ${ }^{a}$ Ramos Gutiérrez, Josefa Mª San Vicente Rodríguez, Pilar Huelin Martín, M $M^{a}$ Inmaculada González García, Margarita Camarero Shelly, Clarisa Reinares Martínez, Laura Villanova Cuadra, Rosa Ma Gómez del Forcallo. HC Doctor Cirajas: Francisco Endrino Gómez, Ma Rosario Ferreras Eleta, Luis De Vicente Aymat, María Santos Santander Gutiérrez, Alicia Mateo Madurga. HC Juncal: Nuria Caballero Ramírez, Ana Morán Escudero, Mercedes Rodríguez Franco, Ma Luz Meiriño Pérez, Ma Mar Zamora Gómez, Francisco Vivas Rubio, María Martín Martín. HC Miguel de Cervantes: Rafael Pérez Quero, Ma Isabel Manzano Martín, Raimundo Pastor Sánchez, Alicia Herrero de Dios, Cesar Redondo Luciáñez. HC Reyes Magos: Cristina Casado Rodríguez, Luisa María Andrés Arreaza, Pilar Hombrados Gonzalo, Soledad Escolar Llamazares, Francisco López Ortiz, Luz Ma del Rey Moya, Isabel Rodríguez López. HC Calesas: Diego Martín Acicoya, Pilar Kloppe Villegas, 
Isabel García Amor, Magdalena Canals Aracil, José Javier Gómez Marco, Alberto González Álvaro, Fco Javier San Andrés Rebollo, Inés González López, Isabel Herreros Hernanz, Antonio Revuelta Alonso, Nieves Calvo Arrabal, Ma Milagros Jimeno Galán, Rosa García Hernández. HC Guayaba: Tomás Gómez Gascón, Concepción Vargas-Machuca Cabañero, Ma Isabel Gutiérrez Sánchez, Ma Angeles Fernández Abad, Margarita Beltejar Rodríguez, Javier Martínez Suberviola, Miguel Angel Real Pérez, Carmen Coello Alarcón, Carlos San Andrés Pascua, José Antonio Granados Garrido. HC General Ricardos: Santiago Machín Hamalainen, Raquel Mateo Fernández, Cristina de la Cámara Gonzalez, José D.Garcés Ranz, Asunción Prieto Orzanco, Ma Teresa Marín Becerra, Paulino Cubero González, Francisco R. Abellán López, Olga Álvarez Montes, Mercedes Canellas Manrique, Ma José San Telesforo Navarro, Ma Mercedes Parrilla Laso, Ma Ángeles Aragoneses Cañas, Angela Auñón Muelas HC Los Yébenes, Esther Valdés Cruz, Consuelo Mayoral Lopez, Teresa Gijon Seco, Francisca Martinez Vallejo. HC Valle Inclán: Ana Isabel Menéndez Fernández, Ma del Mar De la Peña González, Ma Ángeles Maroto García, María Sánchez Cristóbal. HC Lavapiés: Ma Carmen Álvarez Orviz, Jesús Herrero Hernández, Mạ Veredas González Márquez, Ma Jesús López Rodríguez, Maa de las Maravillas Almarza García, Ma Teresa San Clemente Pastor, Ma Ámparo Corral Rubio. HC Colmenar Viejo Norte: Gonzalo Ruiz Zurita, Ángela Allue Bergua, Marta Cabrera Orozco, Ma del Puerto De Antonio García, Ana Isabel Cerezo Diviu, Inmaculada Solsons Roig, Pilar Gómez de Abia. HC Fuentelarreina: María Concepción Díaz Laso, Ma Luisa Asensio Ruiz, Carmen Siguero Pérez. HC Presentación Sabio: Antonio Molina Siguero, Inmaculada Cerrada Puri, Paloma Rodríguez Almagro, Rosa Rosanes González, Ma Carmen Pérez García. HC Cuzco: Mar Noguerol Álvarez, Ma Ángeles de Miguel Abanto, Ma Lourdes Reyes Martínez, Pilar Gutiérrez Valentín, Jorge Gómez Ciriano, Raquel Calzada Benito, Carolina Torrijos Bravo, David Ferreiro González, Judit León González. HC San Martín de Valdeiglesias: Nuria Tomás García, Alberto Alcalá Faúndez, Eva Fernández López, Inés Melero Redondo, Ricardo González Gascón. HC Pedroches: Jeannet Sánchez Yépez, Mercedes del Pilar Fernández Girón, Beatriz López Serrano, Mã Teresa Rodríguez Monje, Paloma Morso Pelaez, María Cortes Duran, Carolina López Olmeda, Almudena García- Uceda Sevilla, Dolores Serrano González, Inmaculada Santamaría López. HC Mendiguchía Carriche: Francisca García De Blas González, Alberto López García-Franco, Amaya Azcoaga Lorenzo, Mar Álvarez Villalba, Belén Pose García. HC Santa Isabel: Rosa Fernández García, Francisco de Alba Gómez, Antonio Redondo Horcajo, Beatriz Pajuelo Márquez, José Luis Gala Paniagua, Encarnación Cidoncha Calderón, Ángel Delgado Delgado, Ma Jesús Gómez Martín, José Francisco Ávila Tomas. HC El Greco: José Enrique Mariño Suárez, José Luis Quintana Gómez, José Antonio González-Posada Delgado, Enrique Revilla Pascual, Esperanza Duralde Rodríguez, Milagros Beamud Lagos. HC Arroyo de la Media Legua: Leonor González Galán, María Verdugo Rosado, Luis Nistal Martín de Serranos, Ma Jesús López Barroso, Mariano Rivera Moreno, Margarita Torres Parras, Ma Reyes Delgado Pulpon, Elena Alcalá Llorente. HC Federica Montseny: Sonsoles Muñoz Moreno, Ana María Ribao Verdugo, María Jesús Fidalgo Baz, Isabel Vaquero Turiño, Ana María Jeú Fidalgo Baz, Clementa Sanz Sanchez, Ana María Sánchez Sempere, Javier Martínez Sanz, María Isabel Arratibel Elizondo. HC Buenos Aires: Paloma González Escobar, Javier Muñoz Gutiérrez, Raquel Baños Morras, Carmen Molins Santos, Ana María Ibarra Sánchez, Cecilio Gómez Almodóvar, Cristina Cassinello Espinosa.

Received: 4 May 2012 Accepted: 31 May 2012

Published: 31 May 2012

\section{References}

1. Dharmarajan TS, Norkus EP: Approaches to vitamin B12 deficiency. Early treatment may prevent devastating complications. Postgrad Med 2001, 110(1):99-105. quiz 106.

2. Kuzminski AM, Del Giacco EJ, Allen RH, Stabler SP, Lindenbaum J: Effective treatment of cobalamin deficiency with oral cobalamin. Blood 1998, 92 (4):1191-1198.

3. Vidal-Alaball J, Butler CC, Cannings-John R, Goringe A, Hood K, McCaddon A, et al: Oral vitamin B12 versus intramuscular vitamin B12 for vitamin B12 deficiency. Cochrane Database Syst Rev 2005, 3(3):CD004655.

4. Dali-Youcef $N$, Andres E: An update on cobalamin deficiency in adults. Q/M 2009, 102(1):17-28

5. Clarke R, Evans J, Schneede J, Nexo E, Bates C, Fletcher A, et al: Vitamin B12 and folate deficiency in later life. Age Ageing 2004, 33:34
6. Ortega RM, Mena MC, Faci M, Santana JF, Serra-Majem L: Vitamin status in different groups of the Spanish population: a meta-analysis of national studies performed between 1990 and 1999. Public Health Nutr 2001, 4(6A):1325-1329.

7. Garcia-Closas R, Serra-Majem L, Sabater-Sales G, Olmos-Castellvell M, SallerasSanmarti L: Distribución de la concentración sérica de vitamina C, ácido fólico y vitamina B12 en una muestra representativa de la población adulta de Cataluña. Med Clin (Barc) 2002, 118(4):135-141.

8. Henriquez P, Doroeste J, Deulofeu R, Fiuza M, Serra-Majem L: Nutritional determinants of plasma total homocysteine distribution in the Canary Islands. Eur J Clin Nutr 2007, 61:111.

9. Lindenbaum J, Rosenberg IH, Wilson PW, Stabler SP, Allen RH: Prevalence of cobalamin deficiency in the Framingham elderly population. Am J Clin Nutr 1994, 60(1):2-11.

10. Pautas $E$, Cherin P, De Jaeger C, Godeau P: Vitamin B 12 deficiency in the aged. Presse Med 1999, 28(32):1767-1770.

11. xvan Asselt DZ, Blom HJ, Zuiderent R, Wevers RA, Jakobs C, van den Broek WJ, et al: Clinical significance of low cobalamin levels in older hospital patients. Neth J Med 2000, 57(2):41-49.

12. Smith DL: Anemia in the elderly. Am Fam Physician 2000, 62(7):1565-1572.

13. Savage DG, Lindenbaum J, Stabler SP, Allen RH: Sensitivity of serum methylmalonic acid and total homocysteine determinations for diagnosing cobalamin and folate deficiencies. Am J Med 1994, 96(3): 239-246.

14. Little DR: Ambulatory management of common forms of anemia. Am Fam Physician 1999, 59(6):1598-1604. 15.

15. Rasmussen K: P-methylmalonate and P-homocysteine: metabolic markers of vitamin deficiencies. Background, validity and applications. Ugeskr Laeger 1996, 158(27):3913-3918.

16. Herrmann W, Schorr H, Bodis M, Knapp JP, Muller A, Stein G, et al: Role of homocysteine, cystathionine and methylmalonic acid measurement for diagnosis of vitamin deficiency in high-aged subjects. Eur J Clin Invest 2000, 30(12):1083-1089.

17. Klee GG: Cobalamin and folate evaluation: measurement of methylmalonic acid and homocysteine vs vitamin B[12] and folate. Clin Chem 2000, 46(8 Pt 2):1277-1283.

18. Andres E, Federici L, Affenberger S, Vidal-Alaball J, Loukili NH, Zimmer J, et al: B12 deficiency: a look beyond pernicious anemia. J Fam Pract 2007 56(7):537-542

19. Andres E, Dali-Youcef N, Vogel T, Serraj K, Zimmer J: Oral cobalamin (vitamin B(12)) treatment An update. Int J Lab Hematol 2009, 31(1):1-8.

20. Nilsson M, Norberg B, Hultdin J, Sandstrom H, Westman G, Lokk J: Medical intelligence in Sweden. Vitamin B12: oral compared with parenteral? Postgrad Med J 2005, 81(953):191-193.

21. Canales MA, de Paz R, Hernandez-Navarro F: Oral cobalamin therapy: a note of caution. Med Clin (Barc) 2007, 128(19):757.

22. Federicia L, Henoun Loukilib N, Zimmerc J, Affenbergera S, Maloiseld D, Andrèsa E: Manifestations hématologiques de la carence en vitamine B12: données personnelles et revue de la littérature. Rev Med Interne 2007, 28(4):225-231.

23. Shatsky M: Evidence for the use of intramuscular injections in outpatient practice. Am Fam Physician 2009, 79(4):297-300.

24. Rabuñal $R$, Monte $R$, Peña $M$, Bal $M$, Gómez A: ¿Debemos utilizar la vía oral como primera opción para el tratamiento del déficit de vitamina B12? Rev Clin Esp 2007, 207(4):179-182.

25. Bolaman Z, Kadikoylu G, Yukselen V, Yavasoglu I, Barutca S, Senturk T: Oral versus intramuscular cobalamin treatment in megaloblastic anemia: a single-center, prospective, randomized, open-label study. Clin Ther 2003, 25(12):3124-3134.

26. Nyholm E, Turpin $P$, Swain $D$, Cunningham $B$, Daly $S$, Nightingale $P$, et al: Oral vitamin B12 can change our practice. Postgrad Med J 2003, 79 (930):218-220.

27. Kwong JC, Carr D, Dhalla IA, Tom-Kun D, Upshur RE: Oral vitamin B12 therapy in the primary care setting: a qualitative and quantitative study of patient perspectives. BMC Fam Pract 2005, 21(6):1-8.

28. van Walraven $C$, Austin $P$, Naylor CD: Vitamin $B 12$ injections versus oral supplements. How much money could be saved by switching from injections to pills? Can Fam Physician 2001, 47:79-86.

29. Vidal-Alaball J, Butler CC, Potter CC: Comparing costs of intramuscular and oral vitamin B12 administration in primary care: a cost-minimization analysis. Eur J Gen Pract 2006, 12(4):169-173. 
30. Graham ID, Jette N, Tetroe J, Robinson N, Milne S, Mitchell SL: Oral cobalamin remains medicine's best kept secret. Arch Gerontol Geriatr 2007, 44(1):49-59.

31. Mariño-Suarez JE, Monedero-Recuero I, Pelaez-Laguno C: B12 vitamin deficiency and oral treatment. An option as efficient as (still) infrequently used. Aten Primaria 2003, 32(6):382-387.

32. Andres $E$, Federici L: Role of vitamin B 12 in anemia in old age. Arch Int Med 2009, 169(12):1167-1168.

33. Eussen SJ, de Groot LC, Clarke R, Schneede J, Ueland PM, Hoefnagels WH, et al: Oral cyanocobalamin supplementation in older people with vitamin B12 deficiency: a dose-finding trial. Arch Intern Med 2005, 165(10): 1167-1172.

34. Guidelines and Protocols Advisory Committee: Cobalamin (vitamin B12) Deficiency - Investigation \& Management [Internet]. Victoria: British Columbia Medical Association; http://www.bcguidelines.ca/pdf/cobalamin.pdf.

35. Lederle FA: Oral cobalamin for pernicious anemia. Medicine's best kept secret? JAMA 1991, 265(1):94-95.

36. D'Agostino RB, Massaro JM, Sullivan LM: Non-inferiority trials: design concepts and issues - the encounters of academic consultants in statistics. Statist Med 2003, 22:169-186.

37. Powers JH, et al: Sample size and ethics non-inferiority trials. Lancet 2005, 366:24-25.

38. Jones B, Jarvis $P$, Lewis JA, Ebbutt AF: Trials to assess equivalence: the importance of rigorous methods. BMJ 1996, 313:36-39.

39. Pinto JL, Abellán JM, Sánchez Fl: Incorporación de las preferencias de los pacientes en la toma de decisiones clínicas. Barcelona: Ed Masson; 2004

40. Hvas AM, Juul S, Nexo E, Ellegaard J: Vitamin B-12 treatment has limited effect on health-related quality of life among individuals with elevated plasma methylmalonic acid: a randomized placebo-controlled study. J Intern Med 2003, 253:146-152.

41. Piaggio G, Elbourne DR, Altman DG, Pocock SJ, Evans SJ: Reporting of noninferiority and equivalence randomized trials: an extension of the CONSORT statement. JAMA 2006, 295:1152-1160.

42. Egger $M$, Juni $P$, Bartlett $C$ : Value of flow diagrams in reports of randomized controlled trials. JAMA 2001, 285:1996-1999.

doi:10.1186/1471-2458-12-394

Cite this article as: Sanz-Cuesta et al:: Oral versus intramuscular administration of vitamin B12 for the treatment of patients with vitamin B12 deficiency: a pragmatic, randomised, multicentre, non-inferiority clinical trial undertaken in the primary healthcare setting (Project OB12). BMC Public Health 2012 12:394.

\section{Submit your next manuscript to BioMed Central and take full advantage of:}

- Convenient online submission

- Thorough peer review

- No space constraints or color figure charges

- Immediate publication on acceptance

- Inclusion in PubMed, CAS, Scopus and Google Scholar

- Research which is freely available for redistribution 